\title{
Novas Tendências da Criminalidade Telemática
}

\author{
Marcelo Xavier de Freitas Crespo' \\ Spencer Toth Sydow ${ }^{2}$
}

\section{Introdução}

Enquanto nosso Estado parece cada vez mais desprotegido e vulnerável a ataques da criminalidade individualizada e organizada, surgem, em progressão geométrica e a cada momento, novos instrumentos e maneiras de lesar as pessoas por meio da telemática.

A telemática é a comunicação à distância, aqui tratada por um conjunto de serviços informáticos fornecidos através de uma rede de telecomunicaçōes, satélites e tecnologias, e que, por ser dinâmica ao extremo, possibilita a criação constante de novas técnicas criminosas.

Desde a criação da Internet os meios de relacionamento sofrem evolução contínua. São diversos os novos meios de se comunicar como os comunicadores instantâneos, as páginas de relacionamento, os diários virtuais ou blogs, os aparelhos handhelds e palmtops etc. Enfim, a comunicação atual é dotada de uma gama variadíssima de possibilidades e instrumentos.

Não há dúvidas de que o tema em questão está mudado no exato momento em que se lê este artigo. O que denominamos "nova tendência da criminalidade" guarda relação direta com o uso de tecnologia moderna a desserviço social e em

\footnotetext{
Advogado, graduado pela FADI, professor de Direito Penal, Mestrando em Direito Penal pela Universidade de São Paulo.

2 Advogado, graduado pela PUC-SP, professor de Direito Penal, Mestrando em Direito Penal pela Universidade de São Paulo.
} 
favor de práticas delituosas e pode já ter sido superada uma vez que a tecnologia aliada à criatividade e ao conhecimento técnico daqueles usuários de aparelhos está sempre em contínua mudança e evolução.

Ao discorrermos sobre as novas tendências dos crimes telemáticos, devemos, antes de tudo, escolher uma dentre as diversas classificações dos crimes eletrônicos seguida por uma demonstração da situação da criminalidade atual em face das práticas reiteradas. Apenas em seguida, e com base em hodiernas práticas, buscaremos uma projeçāo da criminalidade de acordo com as tendências das novas tecnologias.

Destarte, o panorama que pretendemos criar passa por breves relatos de ocorrências cotidianas, denúncias de métodos de violação de direitos, de formas de explorar brechas na segurança dos aparelhos e serviços, sempre buscando ilustrar com exemplos e definiçōes, uma vez que a linguagem da criminalidade telemática é, em regra, especializada e na língua inglesa. A demonstração de algumas das mais recentes técnicas para violar direitos individuais também estará distribuída neste artigo, e será seguida de recomendações de segurança para evitar o possível crescimento nas práticas de exploração das fragilidades dos cidadãos.

\section{Classificação}

Adotada por Ivete Senise Ferreira, Vicente Greco Filho e, inclusive, citada por Paulo Marco Ferreira Lima, a classificação que melhor parece se adequar ao temário em voga é a de Herzé Corze e Yves Bismuth, que categorizam dicotomicamente os crimes informáticos como:

- condutas delituosas perpetradas contra um sistema de informática, sejam quais forem as motivações do agente; $\mathrm{e}$

- crimes cometidos contra outros bens jurídicos, por meio de um sistema de informática.

Ainda que o objeto deste artigo não se limite aos crimes cometidos exclusivamente por intermédio de um computador em sentido estrito, parece-nos mesmo que a divisão em meios eletrônicos como objeto protegido (bem jurídico) e meios eletrônicos como meio/instrumento de se lesionar outros bens é a melhor das classificações, por ser mais ampla e permitir melhor discorrermos acerca das práticas.

\section{Segurança telemática}

Ainda no mesmo intuito de facilitar a compreensão das práticas criminosas atuais e dos focos almejados pelos agentes, também será de muita valia classificar os 3 (três) requisitos básicos que compõem a segurança de um sistema informático, quais sejam: 
1. confidencialidade;

2. integridade; e

3. disponibilidade.

Por confidencialidade, entende-se o objeto ideológico do sistema de informação, qual seja, o conteúdo e sua veracidade, resguardada pela privacidade. A integridade está ligada à idéia de materialidade do documento e da autenticidade do meio em que o conteúdo se encontra e se viabiliza. Finalmente, no que se refere à disponibilidade, deve-se entender por possibilidade e/ou capacidade de se acessar o conteúdo em seu meio íntegro.

Desta feita, e paralelamente ao estudo da teoria geral das provas, surge também a necessidade de se classificar o sistema de dados como público ou privado, de acordo com o conteúdo e a tipo de pessoa que o criou e mantém. Naqueles casos, certamente para sistemas públicos de informação vigerá a exigência da certificação digital por criptografia de chave pública e chave privada de acordo com a MP 2.200-2. Para bancos de dados provados, a segurança dependerá dos indivíduos que dispõem de tal direito.

Há, via de regra, duas formas de se perpetrar um ataque através dos meios telemáticos: utilizando-se (i) de recursos da tecnologia como meio de ataque e (ii) utilizando da persuasão sobre usuários e, através de meios tecnológicos, consolidar o golpe. No primeiro caso, a tecnologia é requisito sine qua non para a prática do ato, por exemplo, nos casos de instalação automática de trojans $^{3}$ para monitorar os acessos de um usuário e obter senhas ou números de cartão de crédito sem uma atitude positiva do usuário. No segundo, é a inventividade e a capacidade de ludibriar o alvo que constituem o golpe, sendo a tecnologia somente um meio de comunicação; exemplos nesses casos são os e-mails que, através de sua técnica argumentativa, levam o usuário a, por si, ceder números privativos ou dados pessoais por telefone, carta, ou até mesmo por e-mails ou sites. No primeiro caso, o golpista utiliza-se de uma vulnerabilidade da tecnologia que permite a instalação muitas vezes imperceptível de um código espião prejudicial. No segundo caso, existe a exploraçāo de uma vulnerabilidade humana, seja por falta de conhecimento, seja por ingenuidade do usuário que espontaneamente cede os dados.

\section{Tecnologias}

Para desenvolver o tema proposto, temos, também, que limitar quais tecnologias serão tratadas ao considerar as novas tendências. Desta feita, trataremos das novas tendências da criminalidade telemática especificamente quanto à utilização de computadores (e aqui englobaremos desde computadores de mesa, notebooks

Trojan é um código malicioso (malware - malicious software) que compōe um programa capaz de executar açōes prejudiciais e danosas a um sistema informático. 
até PDAs e palmtops), bem como e-mails, navegação por sites e uso de tecnologia VoIP para telefonia e da telefonia móvel (mensagens SMS, mensagens MMS, recursos especiais de aparelhos e, ainda, da tecnologia bluetooth e infravermelha).

\section{Criminalidade e o uso do computador}

\section{Vírus, Worms, Rootkits, Trojans, Spywares e Keyloggers}

Dentre os recentes modos desenvolvidos para se praticar delitos informáticos com o uso de recursos da tecnologia como meio de ataque, temos que mencionar a existência de (i) vírus, (ii) worms, (iii) keyloggers, (iv) trojans, os (v) rootkits e os (vi) spywares.

Antes de mais nada, há que se ter em mente que a nova criminalidade exige e exigirá cada vez mais dos operadores do direito o conhecimento de termos informáticos. Mais do que isso, terão os juristas que conhecer, com certa intimidade, a funcionalidade dos equipamentos eletrônicos e seus programas para compreender com maior propriedade o alcance dos delitos. Talvez se torne, inclusive, necessária a especialização do direito nesta área através de cursos multidisciplinares e não exclusivamente legais.

Todavia, cremos não ser o caso de se exigir que operadores do direito sejam técnicos em informática para que possam analisar eventuais condutas criminosas. Não se trata disso. Até porque, hoje, já há ciências bastante complexas que não são de conhecimento dos juristas, mas que, ainda assim, permitem considerações sobre determinados assuntos, uma vez que podem valer-se de auxiliares especializados. Tome-se, por exemplo, o recente caso de que se tem tratado como o "mais grave acidente aeronáutico da história brasileira" em que um jato particular colidiu com um avião comercial causando a perda de dezenas de vidas. Obviamente não se exigirá do delegado do caso, do promotor de justiça e nem do magistrado que conheçam os termos técnicos e que possam, por si mesmos, compreender as informações constantes na "caixa-preta" dos aviões e outros equipamentos tecnológicos existentes. Mas é inegável que termos técnicos virão à baila. $\mathrm{E}$ que sua compreensão facilitará sobremaneira o julgamento das eventuais ações penais e civis, vez que, para que haja plena cognição do alcance do fato jurídico, é necessário compreender sua abrangência e seu modus operandi.

Assim, diante da inegável evolução da tecnologia, reafirmamos que cada vez mais os termos técnicos informáticos farāo parte da prática jurídica, inclusive no âmbito penal.

Tratando, então, de práticas que em tese são delituosas, é preciso ter em mente certas definições e compreensões. A primeira delas é a de vírus. Vírus são segmentos de códigos de computação que se anexam a programas ou sistemas de modo a se propagar pelas máquinas e contaminar outros sistemas em contato com esta, através de e-mails remetidos automaticamente e até mesmo por transmissão 
de dados maliciosos por outros métodos. Sua criação se dá com o intuito de explorar falhas de segurança e se multiplicar, o que geralmente se dá com o auxílio humano através da circulação de arquivos que contenham tais malwares.

Tal como os vírus que atacam os seres humanos, os vírus da informática podem variar quanto ao seu grau de destruição, podendo trazer ao usuário de um computador mero inconveniente no uso do sistema (lentidão, incapacidade de acessar arquivos, dentre outros) bem como a total perda de dados e corrupção de arquivos.

Em suma, vírus nada mais são que programas como outros tantos. Sua peculiaridade está no fato de que, enquanto normalmente os programas visam a um aumento na produtividade no ambiente de trabalho, o vírus intentará atravancálo, destruí-lo, dificultar-lhe o funcionamento.

O fato é que cada vez mais os vírus são criados e disseminados. Um programa malicioso desses, ao ser instalado no computador de alguém, pode proporcionar danos seríssimos ao sistema. Basta dizer que todo o conteúdo de um disco rígido pode se perder, o que pode significar anos de trabalho e pesquisa que se vão num piscar de olhos. Obviamente, há vírus menos catastróficos que, por exemplo, apenas deixam o sistema mais lento ou mostram alguma mensagem com conteúdo divertido ou pornográfico.

E, nesse aspecto, podemos aqui vislumbrar uma nova espécie de perturbação da tranqüilidade. Imagine alguém navegando tranqüilamente pelo ambiente da web, quando, de repente, ao acessar um sítio qualquer, recebe um vírus que faz surgir em sua tela uma imagem de pessoa nua, anunciando algo relativo ao sexo. Tal fato muito se assemelha com o previsto no art. 65 da Lei de Contravenções Penais (perturbação da tranqüilidade). Não podemos falar em importunação ofensiva ao pudor, vez que esta se dá apenas em lugares públicos, o que nem sempre se dará quando nos referimos à imagem veiculada pela telemática. Também a importunação ofensiva ao pudor no mais das vezes se dá pelo uso inconveniente de palavras e gestos e, no caso, referimo-nos a veiculação de imagem pornográfica pelo funcionamento de um vírus. Merece ainda ser dito que já há legislação penal alienígena que prevê como crime o simples fato de se ter arquivos com conteúdo pornográfico em seu computador. In casu, incrimina-se a posse de arquivos com conteúdo pornográfico, ainda que não haja veiculação deles. É, mais uma vez, a incriminação do risco, do perigo. Qual o bem jurídico ofendido nessa conduta? Trata-se de questão das mais atuais, qual seja, a função do direito penal e sua proteção a bens jurídicos. Todavia, o que se propõe neste trabalho é uma apresentação de nova criminalidade, de forma que referidas discussões merecem obras mais específicas.

Em assim sendo, nāo obstante o viés pornográfico que um vírus pode apresentar, nota-se que a simples disseminação de um programa malicioso pode causar incalculáveis perdas a quem quer que seja, considerando, nesta gama, inclusive a inacessibilidade de banco de dados importantes. Isso porque um vírus pode ter 
ínsito o poder de devastar (apagar) registros contidos dentro de um computador. Por isso, não se pode mais ignorar um comportamento que vise criar ou espalhar vírus. Até por isso, esta conduta está tipificada nos Projetos de leis 84 e 89 de 2003 (da Câmara dos Deputados) e 76 e 137 de 2000 (do Senado). Vejamos:

"Art. 163-A Criar, inserir ou difundir vírus em dispositivo de comunicação, rede de computadores ou sistema informatizado, com a finalidade de destruí-lo, deteriorá-lo, alterá-lo ou dificultar-lhe o funcionamento.

Pena: reclusão de 01 a 03 anos e multa.

Parágrafo único. A pena é aumentada de sexta parte se o agente se vale de nome suposto ou da identidade de terceiros para a prática do crime."

Como se vê, o legislador não está totalmente alheio à evolução tecnológica. Até porque a evolução social-tecnológica levou a uma multiplicação em progressão geométrica desses malwares levando empresas a perderem milhões de dólares com inconvenientes promovidos pelos arquivos maliciosos, bem como pessoas físicas.

Há que se notar, certamente, que os projetos de lei propõem acrescer a letra $A$ ao artigo 163 do Código Penal, que trata especificamente do crime de DANO, inserido no capítulo dos "Crimes contra o Patrimônio". Entretanto, parece-nos que ainda cabe discussão acerca da alocação do tipo apontado dentro do sistema penal brasileiro. Primeiro pelo fato de que o Título II da Parte Especial aponta para crimes que lesionam o patrimônio material. Assim, há que se debater com consciência o fato de que há divergências doutrinárias acerca da materialidade do sistema informático, bem como do software e dos dados computacionais. Não raro se vê defender que a criminalidade em que o bem jurídico atacado é virtual ou imaterial deveria estar no título seguinte ${ }^{4}$ do Código. Certamente, também, é de se notar que ao se tipificar a figura do contágio por vírus, criou-se uma norma penal em branco, de composição heterogênea, uma vez que há de se notar que o conceito de vírus deverá ser buscado em outra ciência e que as tecnologias tenderão a conseguir burlar um conceito estático. ${ }^{5}$

Inegável dizer que vírus causam sérios danos. E é justamente aqui que devemos centrar nossas atenções. Obviamente, quando pensamos em um disco rígido, não temos dificuldades para considerá-lo como "coisa móvel". E, em relação a isso, bem dizia Mirabete (Manual de direito penal, v. 2, p. 224), "coisa, em direito penal, é termo que tem sentido diverso daquele empregado no direito civil. É toda substância corpórea, material, ainda que não tangivel, suscetivel de apreensão e transporte, incluindo os

\footnotetext{
4 Título III - Dos Crimes Contra a Propriedade Imaterial.

5 Observe-se a engenhosidade para dificultar a conceituação de vírus, por exemplo, com a criação de "eVade o' Matic Module" (tradução livre: "Módulo de Evasão Automática" ou simplesmente VoMM) - um programa que embaralha os códigos de diversos malwares já conhecidos por se aproveitarem de brechas de segurança nos navegadores da web (browsers) para assim torná-los irreconheciveis para os antivírus. In: <http://wnews.uol.com.br/site/noticias/materia.php?id_secao $=4 \&$ id_conteudo $=6279>$.
} 
corpos gasosos, os instrumentos ou títulos (quando não se tratar de documento cuja subtração configure o art. 305), e também as partes do solo, ou da casa, árvores, navios e aeronaves, etc., que são imóveis ou equiparados a estes para os efeitos civis. Já se tem decidido que os acessórios do imóvel, como árvores, por exemplo, uma vez mobilizados, constituem objeto do crime de furto".

Dessa forma, é possível argumentar que um vírus que destrua, inutilize ou deteriore coisa móvel (como um disco rígido) é causador de um crime de dano, já tipificado em nosso Código Penal. Todavia, o tipo proposto nos projetos de lei acima citados vai um pouco além, porque criminaliza a própria criação, inserção e disseminaçāo dos vírus, o que nos parece salutar, mas parcialmente incompatível com o capítulo.

O que ainda causa certo tormento é discussão sobre um dano causado por um vírus em um arquivo digital. Deve o arquivo digital, como por exemplo um texto redigido no processador de texto, ser considerado como coisa? E como coisa móvel? E mais: poder-se-ia considerar um arquivo digital como sendo um "documento"? Como se vê, o cerne da questão será a dificuldade em encarar a natureza jurídica dos arquivos digitais.

Sabemos que a doutrina é uníssona em considerar documento todo o suporte material que represente, por escrito, a idéia de alguém, que traga em seu conteúdo relevância jurídica. ${ }^{6}$ Dessa forma, nos moldes acima delineados podemos apontar, como exemplo, um contrato de locação (devidamente impresso e assinado pelas partes). Entretanto, um arquivo de computador que contenha o contrato de locação digitalizado (quiçá assinado digitalmente), guardado no disco rígido do hardware, não se enquadra no conceito tradicional. Da mesma forma estão excluídas as fotografias, pinturas e desenhos digitalizados. Por outro lado, em razão da revolução tecnológica retro aludida não há como ignorar a existência e importância do contrato digital. Insistir no conceito clássico de documento, resistindo às novas tendências tecnológicas, é, no mínimo, um posicionamento demasiado conservador.

Entendemos que um novo conceito de documento não pode tomar por base um suporte físico, material. Também não discutimos a dificuldade de definir-se o conceito, obviamente em razão de se tratar de coisa incorpórea, intangível.

Assim, o documento eletrônico pode se apresentar em forma de vídeos, sons, textos, desenhos ou mesmo fotos. Isso ocorre porque nada mais é que uma parcela de informação eletrônica ou, em outras palavras, um dado eletrônico.

Nesses termos, um dado eletrônico é uma seqüiência pré-ordenada de bits, codificados e decodificados por programas de computador e que são capazes de representar idéias ou fatos (pois formam um vídeo, uma parcela de um texto, uma foto etc.).

\footnotetext{
6 E, quanto à particularidade da falsidade documental, ver a belíssima obra de Sylvio do Amaral. Falsidade documental. Campinas: Ed. Millennium, 2000.
} 
Outro e derradeiro detalhe sobre um documento digital é o fato de não se falar em (versão) "original". Ou, nas palavras de Marcacini ( $O$ documento eletrônico como meio de prova) "o documento eletrônico é a seqüência de bits e, onde quer que esteja gravado, em qualquer quantidade de cópias, mas desde que seja reproduzida exatamente na mesma seqüência".

Tendo uma noção do que sejam vírus, mister se faz analisar os worms. Estes nada mais são que uma espécie de vírus, mas que se reproduzem automaticamente. Enquanto os primeiros dependem que os usuários do computador os enviem de qualquer forma para outro, os worms, uma vez dentro do sistema, multiplicamse, causando desde lentidão na máquina até mesmo a perda de dados e propagação de si mesmos para outros sistemas. Também, em alguns casos, possibilitam que a máquina infectada seja controlada remotamente, ou seja, algumas espécies permitem que, uma vez dentro de um sistema, possibilitem que um terceiro possa ler arquivos, acessar contas, excluir programas, espionar intimidade etc.

Na mitologia fala-se do Cavalo de Tróia numa história grega em que um aparente presente dado ao Rei como bajulação era, na realidade, uma armadilha, vez que tinha em seu interior soldados que acabaram por tomar a cidade de Tróia. Os trojan horses ou apenas trojans são a versão moderna dessa fraude. Isto é, são programas que aparentam ter utilidade, mas que trazem escondidos em si alguma espécie de malware invasivo e que possibilitam o cometimento de atividades prejudiciais aos usuários de um computador. Eles, em regra, não se espalham automaticamente, como os worms.

Já os rootkits nada mais são que trojans específicos que permitem que o computador seja controlado remotamente. Ou seja, são programas que trazem escondidos em si códigos maliciosos que dão a um terceiro a capacidade de controle de uma máquina contaminada. O nome justifica-se em razão de serem, inicialmente, kits de programas (para a plataforma Linux/Unix). A finalidade desses kits é dar acesso total ao sistema previamente comprometido (infectado pelo programa), de modo a causar transtornos ao usuário. Em termos técnicos, diz-se que os rootkits atuam como backdoors ("portas de fundo" que, geralmente, são abertas e servem como entrada disfarçada), isto é, permitem que a máquina infectada possa ser controlada. Ademais, o termo root é usado como sinônimo de usuário com o controle total do computador nas plataformas Unix. Eis a justificativa do nome.

Em outras palavras, um rootkit é um trojan que busca se esconder de softwares de segurança e do usuário utilizando diversas técnicas avançadas de programação. Ele passa despercebido no sistema e dá acesso ao agente a todos os documentos, senhas e arquivos do usuário infectado.

Neste ponto, vale comentar que a prática que conjuga rootkits, vírus, worms e trojans tem sido incorretamente denominada de "seqüestro de dados", quando na verdade deveria ser compreendida como uma extorsão por meio virtual. ${ }^{7}$ Utilizan-

<http://pcworld.uol.com.br/reportagens/2006/11/28/idgnoticia.2006-11-28.8731502882/IDGNoticia_view $>$. 
do-se de códigos maliciosos, o agente viola computador alheio e compacta pastas com arquivos importantes, colocando uma senha com grande número de dígitos. Em seguida, remete $e$-mail ou deixa um documento (nota de "seqüestro") em que comunica ao usuário que seus dados ficarão indisponíveis até que seja feito um pagamento (em regra depósito em dinheiro virtual) ou aquisição de produtos. Assim que o usuário cede às exigências do cracker, ele recebe a senha e volta a dispor de seus arquivos.

Também devemos lembrar dos spywares, que são programas que rastreiam informações do computador, como, por exemplo, os sites que o usuário costuma visitar. São uma espécie de cookie, ${ }^{8}$ mas com intuitos prejudiciais ao usuário. Em sua versão inocente são utilizados como ferramenta para conhecer melhor potenciais clientes, uma vez que rastreando os usuários poder-se-iam pôr em prática propagandas especialmente relacionadas com os interesses do destinatário. Entretanto, há spywares negativos que funcionam espionando as práticas do usuário, inclusive quanto a atividades confidenciais ou protegidas pela intimidade. Ainda, se essa prática não é a mais deletéria em termos de causar danos aos usuários, há que se considerarem as discussões sobre a legalidade deste recurso como prática comercial infringente de intimidade e até mesmo a questão da invasão de privacidade que se impōe às pessoas. ${ }^{9}$

Por fim, há os chamados keyloggers, que são programas que captam as teclas digitadas no teclado do computador ou no teclado virtual, através de cliques. São de extrema valia para a obtenção ilícita de senhas de contas bancárias, cartōes de crédito, acesso a sistemas etc.

Vê-se, portanto, que os vírus e worms são aptos a causar dano. Logo, podem ser instrumentos para o crime. Nesse aspecto, entendemos salutar a tipificação da disseminação de tais malwares. Quanto à criminalização da sua mera criação, somos mais cautelosos. Em tempos de inflação penal, em que atitudes são tipificadas numa crença em que o Direito Penal resolve todos os problemas em violenta agressão ao Princípio da ultima ratio, a tipificação da simples criação de vírus ou worm, em princípio, não protegeria de per se um bem jurídico. Estar-se-ia incriminando um "risco hipotético", isto é, algo além do perigo concreto e além do perigo abstrato. ${ }^{10} \mathrm{O}$ mesmo se diga em relação a considerar-se crime a difusão de malwares.

Destarte, vê-se que, com todas essas definições, teríamos a prática de crimes contra os sistemas informáticos (crimes informáticos puros ou diretos) e contra

\footnotetext{
- Arquivo que guarda informações trocadas entre navegador e servidor de modo a prover rapidez ao acesso informático, o que se dá pela desnecessidade de digitar-se alguns dados quando novamente houver acesso a uma determinada página.

9 <http://pcworld.uol.com.br/noticias/2006/09/20/idgnoticia.2006-09-20.9731627745/IDGNoticia_view?pageNumber $=1>$.

10 Há que se citar que em recente pesquisa feita pelo site da Universidade Harvard acerca dos métodos de contenção de spams, $45 \%$ das opiniōes apontam para melhor tecnologia como soluçāo, em detrimento de esforço juridico, este com apenas $25 \%$ dos votos. In: <http://h2o.law.harvard.edu/ viewRotisserie.do;jsessionid $=2 \mathrm{~B} 9 \mathrm{EA}$ 635FEE5E67B12560ED1C13BFA4B? view $=$ all\&expand $=0$ \&exp andQuestions $=$ none \&expandPolls $=$ \&order $=$ thread \& rotisserield $=547>$.
} 
outros bens jurídicos (crimes informáticos impuros ou indiretos). Estes últimos, notadamente, são as fraudes, como o estelionato, onde o uso da telemática seria apenas um meio para se obter a final vantagem ilícita.

\section{Spamming}

Outro problema que assola a vida tecnológica é o spamming. Prática muito antiga consistente no envio de mensagens comerciais não solicitadas (UCEs ou spams), que prejudica o tráfego de dados e sobrecarrega caixas de mensagem de usuários e empresas. Hoje mais propriamente praticado na modalidade de e-mails, o envio não solicitado já começa a ser prática em telefonia móvel por meio de envio de mensagens de texto e até mesmo mensagens via tecnologia bluetooth.

Objeto de discussão constante acerca de sua criminalização, a remessa maciça de publicidade inicialmente ocorreu com correio tradicional, por conta de haver vendas de bancos de dados de empresas e clientes possibilitando que pessoas jurídicas bombardeassem possiveis consumidores com propagandas. A migração da comunicação levou a prática para os meios eletrônicos, e sua popularização levou ao desenvolvimento de filtros anti-spam para coibir tal prática.

Para alguns, dever-se-ia tipificar a prática ${ }^{11}$ sob argumentação de que a necessidade de um usuário ver-se obrigado a apagar dezenas de mensagens em sua caixa postal levaria a uma espécie de furto de tempo por parte das empresas que fomentam o spam; outro argumento levantado é o de que é costume dos infratores escravizar computadores alheios e obrigá-los a remeter dezenas de e-mails, alastrando e multiplicando a força de envio; ainda, a remessa de spams pode levar a prejuízo a sites e e-mails governamentais, bem como particulares, uma vez que por vezes lotam a caixa de entrada impedindo a realização de negócios, acordos e atos importantes. Outros crêem que a prática traz repercussões meramente na esfera cível, não cabendo ao Direito Penal nenhuma atitude. O fato é que receber muitos e-mails não solicitados pode, definitivamente, atravancar o uso do computador, trazendo sim prejuízo ao bom desenvolvimento das atividades de cada um de nós.

Ainda quanto ao spam, podemos citar algumas práticas recentes que estão tipificadas no Código Penal (art. 196, $\$ 1^{\circ}$, incisos III e VIII), quais sejam os crimes de desvio de clientela e de falsa atribuição de distinção. São (1) o blam, (2) o spim, (3) o MFA e (4) o spamdexing, por consistirem em formas de desviar o usuário internauta de seu objetivo, em prol de uma promoção forçada de sites e produtos. ${ }^{12}$

\footnotetext{
11 Já há países que assumem a prática de spamming como crime como, por exemplo, a Argentina (<http://www.acse.com.ar/shop/detallenot.asp? notid $=699>$ ) e o Estado da Califórnia nos Estados Unidos da América do Norte (<http://www.informationweek.com/news/showArticle.jhtml?articleI $\mathrm{D}=187201638>$ ).

12 Não citaremos os "pop-up ads" por se tratar de uma prática considerada controlada, apesar de crermos ser modalidade de crime de concorrência desleal também, além de, em alguns casos, consistir verdadeira contravenção penal de importunação ao pudor quando as janelas trazem conteúdo pornográfico não solicitado.
} 
1. Blam ou splog - São os chamados blogs de propaganda. São simulações de blogs $s^{13}$ com o fim específico de propagandear. A popularizaçāo dos blogs (e conseqüentemente o alto índice de visitação de blogs populares) fez com que se criassem os blogs-spam que, na fusão de palavras, acabaram por chamar-se blam. São blogs feitos para captar cliques de usuários e, assim, aumentar o ranking de sites específicos, aumentando a captação de dinheiro na forma de patrocínio local, enganando o usuário e fazendo com que acesse site sem a intenção, gerando, assim, visitação. Tais blogs não possuem nenhum tipo de informação aproveitável, mas somente links patrocinadores postados. Assim, o usuário desavisado acaba por acessar e clicar na armadilha que não tem nada de prejudicial (senão a perda de tempo) ao internauta que o acessou, mas somente gera poluição e falsos sites nos mecanismos de buscas, numa enganação lucrativa.

2. Spim - São as propagandas direcionadas aos comunicadores instantâneos como ICQ MSN, AIM, mIRC, Falei!, denominados na língua inglesa como "Instant Messengers" ou Comunicadores Instantâneos por permitirem, com sua tecnologia, a conversa em tempo real de usuários conectados em qualquer região do planeta. As propagandas não solicitadas, costumeiramente enviadas para o e-mail, com a popularização dos IMs, passaram, também, a ser enviadas para usuários conectados. Geralmente são propagandas comerciais (obviamente não solicitadas) e trazem um link para ser clicado e, em seguida, dirigido para aquele anunciante.

3. MFA - Made for AdSense - São os sites feitos exclusivamente com intuito de trazerem conteúdo de propaganda. O proprietário do site cria ou copia trechos de conteúdo de páginas de conceituação elevada na Internet e os coloca em páginas com mínima quantidade de informação mas máxima quantidade de propaganda para tentar fazer com que o usuário que acabe se encontrando por ali clique em alguma propaganda e, assim, remunere o proprietário da página hospedeira de anúncios. Tal prática tem sido feita em quantidade absurda, levando a Internet a verdadeiro caos de propagandas. Tal prática é repudiada pelos internautas, pelos sistemas de busca mas, entretanto, não configura, em regra, nenhum tipo penal se o conteúdo do sítio for original.

4. Spamdexing - Uma espécie de concorrência desleal eletrônica somada a uma propaganda enganosa, consiste em colocar no site palavras aleatórias sem nenhum nexo explicitamente na página em sua parte final, escondida no código fonte ou mesmo camuflada (escrita em preto em áreas de fundo preto, denominada "Black hat: hidden keywords ou cloaking"), levando o usuário a entrar em sites de conteúdo completamente diferente do buscado. Isso se dá por conta de que o usuário procura 
no mecanismo de busca as exatas palavras que estão escritas aleatoriamente nas páginas daquele site. Desta forma, um proprietário de site mal intencionado, para aumentar o número de visitas a seu site e burlar sistemas de busca, enche sua página com palavras de alta incidência na procura dos usuários mesmo sabendo que tais palavras não têm nenhuma relação com seu conteúdo. Desta forma, seu site aparecerá como tendo relação com a palavra digitada no mecanismo de busca, mesmo sem ter nenhuma adstrição, induzindo o internauta, pois, a erro.

\section{Engenharia social}

O que se denominou recentemente de Engenharia Social há muitos anos já se chama ardil ou artifício fraudulento para o Direito Penal. Entende-se como engenharia social todo o método de mascarar a realidade para explorar ou enganar a confiança de uma pessoa detentora de dados importantes a que se quer ter acesso. É o artifício intelectual para acessar informações sigilosas e que, portanto, não utiliza necessariamente de tecnologia, mas sim de qualquer meio de comunicação.

Assim, usando de armadilhas e invenções intelectivas, um agente ativo de conduta delituosa persuade um usuário inocente conquistando sua confiança e fazendo com que ele ceda a informação pretendida acreditando estar fazendo a coisa certa.

A tendência moderna é a de trazer as novas tecnologias para dentro da engenharia social, conjugando-as com os meios carismáticos de persuasāo. Assim, vírus se espalham, spams se propagam, senhas sāo cedidas.

Importante frisar que tanto a prática de spamming quanto a engenharia social são utilizadas em conjunto com tecnologias criminosas desenvolvidas por agentes mal-intencionados, levando, pois, a um cunho criminoso. A engenharia por si só configura crime de estelionato mas, quando somada à invasão de computador alheio e prejuízo à máquina, pode configurar os mais diversos crimes, desde dano até violação de direitos autorais.

\section{Phishing e vishing}

Não nos surpreende haver meios cada vez mais curiosos e sofisticados usados com finalidade criminosa. É o que ocorre especialmente com o phishing scam e com o vishing.

Tratemos primeiramente do phishing scam. Inicialmente, os termos phishing, phishing scam ou mesmo só scam são utilizados indistintamente. Derivam do vocábulo bretão to fish ou fishing, que significa pescar. Podemos dizer que se trata de verdadeira engenharia social que tem como finalidade obter informações relevantes, na modalidade fraude virtual para a obtenção de dados valiosos dos particulares. 
O phishing funciona da seguinte forma: uma pessoa mal-intencionada envia uma mensagem eletrônica (pode ser um e-mail, um recado no Orkut etc.) a outrem e, utilizando-se de pretextos falsos, tenta enganar a pessoa receptora da mensagem e induzi-la a fornecer informaçōes como número do cartão de crédito, senhas, dados de contas bancárias, ou, ainda, instiga a baixar e executar arquivos que permitam a futura subtração ou roubo de informaçōes ou o acesso não autorizado ao sistema da vítima.

Quando por e-mail, um estelionatário envia mensagens falsas utilizando a identidade de entidades populares e consideradas confiáveis como bancos, lojas, sites de entretenimento, empresas de cartão de crédito, órgãos governamentais etc. Normalmente as mensagens são enviadas para inúmeros endereços de e-mail previamente coletados na Internet. Os e-mails normalmente são entregues por computadores controlados por pessoas mal-intencionadas, respaldadas por servidores mal configurados e computadores com conexão banda-larga infectados com cavalos de tróia (trojans) intencionalmente desenvolvidos para permitir o envio de e-mail em massa (spam) ou para manter aberta uma porta de acesso malicioso.

Outra técnica popular é a subtração de identidade via e-mail. E-mails são enviados com o intuito de persuadir usuários a fornecer dados pessoais como o nome completo, endereço, nome dos pais, número de seguridade social, cartōes de crédito, números de conta bancária, entre outros. Se capturados, esses dados podem ser usados para obter vantagens financeiras, seja por meio eletrônico, seja até pela extorsão convencional. A identidade usada nessas mensagens comumente é de órgãos do governo como a Receita Ferderal ou o Banco Central, ou ainda bancos e empresas de cartão de crédito. ${ }^{14}$ Essas mensagens trazem links que direcionam para sites falsos, normalmente muito parecidos com os sites verdadeiros, onde existem formulários que a vítima deve preencher com as informaçōes solicitadas. O conteúdo preenchido no formulário é enviado ao estelionatário que faz o uso que achar mais vantajoso. Outra modalidade recente consiste em informar que foi tomado empréstimo com o número do CPF do usuário e que seu nome irá para as listas de proteção de crédito caso a pessoa não efetue o pagamento; o usuário é dirigido para o site do banco ou imprime boletos e os paga. O golpe está finalizado. ${ }^{15}$

Um dos golpes mais recorrentes quanto ao phishing diz respeito ao roubo de informaçōes bancárias, o que se dá de forma parecida com a do roubo de identidade. A diferença está no fato de que a mensagem recebida contém links que apontam para sites que contêm programas de computador (códigos maliciosos) que, uma vez instalados, podem permitir a captura de informaçōes. A instalação desses

\footnotetext{
1: Reportagem do Caderno Link do Jornal O Estado de S. Paulo de 5 de março de 2007 demonstra que até $90 \%$ dos usuários sāo enganados por phishings bem formulados e acabam cedendo dados ou pagando quantias não autênticas.

15 Em 19 de março de 2007 estavam ativos 11.951 tipos diferentes de phishing, de acordo com o site <www.phishingtank.com>
} 
programas é, na grande maioria, feita manualmente pelo usuário e por ignorância. Tecnicamente pode existir a possibilidade da instalação automática desses programas apenas pela leitura da mensagem, mas isso depende de uma combinação de muitos fatores, o que dificilmente acontece.

No Brasil, o phishing via e-mail não vem apenas com o nome de entidades famosas. São usados diversos tipos de assuntos com o intuito de atrair a curiosidade e fazer com que o receptor da mensagem clique no link contido junto ao corpo do e-mail. É o caso da mensagem que diz ter fotos de pessoas nuas, ou mantendo relações sexuais, convites para participar de programa de televisão e até mesmo venda de carros. Na realidade o link não contém fotos ou formulários, mas sim um arquivo executável, que ao ser baixado e executado instala um cavalo de tróia (trojan) ou um keylogger no computador do usuário.

Muito freqüente também o golpe por meio do envio de cartóes virtuais. Em qualquer dos casos, um detalhe a que o usuário deve prestar a atenção são erros de gramática que essas mensagens geralmente apresentam, além de notar a genuinidade do endereço do site, bem como o sinal de página segura (cadeado na parte inferior da tela) em seu navegador.

Recentemente o alvo mais evidente do phishing tem sido o site Orkut.com, pertencende à empresa Google. Neste site, podem-se deixar mensagens (scraps) no livro de recados do usuário (scrapbook) sendo que a identidade das mensagens é sempre de uma pessoa conhecida da vítima, o que aumenta sensivelmente as chances de sucesso do golpe. O conteúdo do scrap é algo como fotos de festas, fofocas, piadas, entre outras coisas. A mensagem contém link que aponta diretamente para o download de um malware cavalo de tróia de captura de senhas (às vezes, senhas do próprio site). A identidade e senhas são obtidas, no mais das vezes, por phishing do nome de usuário e da senha do Orkut da pessoa que remeteu em tese o recado. Como sempre, a fragilidade principal está na falta de cuidado e excesso de curiosidade dos internautas.

Trata-se do uso malicioso cada vez mais sofisticado da tecnologia, que auxilia a criar e-mails falsos com aparência de verdadeiros e dá circulação rápida e abrangente das chamadas "correntes".

Outra forma recente de criminalidade é o chamado vishing. ${ }^{16}$ Embora não relatada no Brasil, a prática já atingiu clientes de um banco no Estado da Califórnia, nos Estados Unidos da América do Norte, ${ }^{17}$ que receberam mensagens de e-mail pedindo que telefonassem para o seu banco por conta de um problema na conta. O único objetivo, entretanto, era obter informaçōes financeiras, em um novo método criminoso batizado de vishing.

Os criminosos aproveitam-se do recurso de VoIP, uma tecnologia que permite a comunicação por voz pela Internet (protocolo IP). Essa novidade torna possível

16 <http://www.internetnews.com/security/article.php/3619086>.

; $<$ http://www.univision.com/content/content.jhtml?cid=921403>. 
fazer ligações telefônicas entre computadores ligados à rede ou entre computadores conectados e telefones fixos e/ou celulares a custos baixos. Este nada mais é que um phishing baseado na telefonia VoIP ("Voice over Internet Protocol", ou voz sobre IP, isto é, aquela tecnologia em que a voz trafega pelo cabo da Internet, não havendo cobrança de pulsos telefônicos). Em vez de levar a vítima até um site falso, o novo golpe o induz a ligar para um número (pelo sistema VoIP) e declarar seus dados bancários ou então digitá-los para um aparelho capaz de reconhecer o som dos dígitos e registrá-los. O contato telefônico é método que inspira maior confiança e faz com que a vítima ceda seus dados com mais efetividade, uma vez que o agente que atende o telefonema simula ser funcionário da companhia ou banco e transfere a ligação para um falso funcionário responsável que passa a anotar os dados.

O uso do recurso da telefonia VoIP se dá por conta da maior dificuldade de se investigar golpes desta natureza uma vez que as ligações não ficam gravadas, sendo, assim, golpe certeiro que impede o convencimento da materialidade do crime e dificulta sobremaneira a busca pela autoria.

Tanto o phishing quanto o vishing são espécies claras de estelionato. Certamente a obtenção de senhas, numerais e códigos pessoais leva (ou intenta levar) à vantagem econômica por parte do agente ativo do crime que se utiliza da engenharia social e de artifícios tecnológicos ardilosos para induzir o usuário a erro. Uma vez com os dados obtidos, o agente pratica compras pela Internet, faz saques, paga contas, cria documentos falsos, e assim por diante.

O que se tem é que, diferentemente dos crimes contra a honra que trazem em seu sistema uma causa de aumento de $1 / 3$ da pena quando o agente ativo utilizase de meio que facilita a divulgação da ofensa, o crime de estelionato virtual ou estelionato que se utiliza de tecnologia telemática ainda não tem a devida atenção do legislador. $O$ uso da Internet como meio de aplicação de golpe merece atenção e agravamento radical da pena, uma vez que o golpe é praticado a centenas de pessoas de uma só vez. Além disso, os recursos visuais modernos são aptos a enganar com muita facilidade, o que facilita o golpe. Também a idéia de crime continuado por si só não parece ser razoável e eficaz quanto à prática, além do fato das vítimas, grande parte das vezes, nāo apresentarem a notícia do prejuízo obtido.

\section{Criminalidade e o uso da telefonia móvel}

Inicialmente cabe explanar a nomenclatura adotada. A expressão telefonia móvel foi escolhida por conta de, com a adoção de bases tecnológicas de VoIP (Voz sobre Protocolo de Internet), não mais ser o aparelho celular o único a servir para a telefonia de mobilidade. Assim, para abarcar o maior número de tecnologias possível e seus aspectos criminológicos, fez-se tal opção.

A problemática penal que tem surgido com o uso da telefonia móvel se dá principalmente com dois focos: (a) o uso criminoso da tecnologia de telefonia móvel fazendo uso da comunicação por voz - função precípua e típica de qualquer 
aparelho -; e (b) a evolução da tecnologia que tem sido agregada à telefonia móvel como recursos de envio de mensagens, fotos, filmes e dados (como um drive externo), bem como gravação de voz e reprodução de arquivos de áudio - que existirá especificamente em aparelhos mais modernos.

Cada um dos focos traz problemas específicos. Citemos algumas atitudes que poderiam ser cometidas com o uso da tecnologia para telefonia móvel sem, contudo, buscar exaurir o tema, mas tentando citar diversos ângulos da problemática:

1. um usuário de um aparelho celular, através da tecnologia de ocultar seu número de telefone ("número privativo"), comete delitos anônimos e apócrifos;

2. um usuário envia mensagens SMS com conteúdo ameaçador ou injurioso;

3. um usuário envia foto com conteúdo obsceno para alguém, através do envio de mensagens MMS;

4. um usuário envia mensagem de voz ameaçadora através da tecnologia MMS;

5. um usuário ofende outro, deixando na caixa postal do celular conteúdo injurioso;

6. um agente modifica o aparelho celular de outrem para que este emita ondas prejudiciais à saúde;

7. um agente modifica o aparelho celular de outrem para que este emita faíscas, levando um usuário a sofrer lesōes corporais;

8. um agente consegue clonar o número de telefone de aparelho de telefonia móvel;

9. uma pessoa adquire chip com número de telefone celular clonado;

10. usuário baixa filmes, músicas ou toques para seu telefone celular e utiliza sem, contudo, pagar direitos autorais de uso;

11. um agente desbloqueia aparelho celular de operadora específica para que funcione com outras operadoras de telefonia móvel;

12. uma pessoa jurídica, através do uso de tecnologia bluetooth de comunicação, envia para celulares propagandas não solicitadas (bluecasting);

13. por conta de falha na segurança de um telefone móvel, alguém remete mensagens delituosas anônimas através de conexão com tecnologia bluetooth (bluejacking);

14. agente intercepta sinal infravermelho de aparelho celular e copia dados sem permissão;

15. com uso de tecnologia bluetooth e por conta de falhas de segurança, agente copia informações de um aparelho de telefonia móvel (bluesnarfing); 
16. com uso de tecnologia bluetooth e por conta de falhas de segurança, agente apodera-se de dados contidos num aparelho ou modifica a senha do aparelho e exige vantagem econômica ao usuário para devolver acesso ou dados (bluesnarfing de dados);

17. com uso de tecnologia bluetooth e por conta de falhas de segurança, agente invade o aparelho celular de outrem e utiliza-se dos recursos bem como faz ligaçōes sendo o usuário possuidor do aparelho cobrado por serviço não efetuado por si (bluesnarfing de tempo);

18. usuário envia mensagens de e-mail pelo aparelho com conteúdo criminoso;

19. menor de idade acessa site com conteúdo impróprio através de seu aparelho;

20. usuário vende seus números da agenda para pessoas jurídicas interessadas em divulgar propaganda; e

21. agente contamina usuários com vírus que tornam o uso do aparelho móvel lento, disseminam ou destroem dados.

\section{Crimes comuns e a telefonia móvel como ferramenta}

Certamente não é o intuito deste trabalho tratar dos crimes comuns que utilizariam a telefonia móvel como uma ferramenta qualquer, mas sim daqueles que utilizam a tecnologia e as possibilidades inovadoras da mobilidade para elaborarem novas formas de cometimento de delitos.

Assim, de nada adiantaria gastarmos linhas falando de crimes de forma de execução livre, dizendo que o aparelho móvel poderia ser utilizado de arma, por exemplo, num crime simples de lesão corporal, num crime de ameaça prometendo a destruição de um aparelho, de um crime de ameaça por conta de a pessoa ser tecnófoba ou até mesmo por contaminação da água com o lítio da bateria do aparelho.

Os crimes aqui referidos também não são aqueles que têm como bem jurídico protegido o telefone móvel. Assim, crime de dano ao aparelho, dano à bateria, furto de aparelhos ou de chips, roubos de aparelhos, fraudes a seguros contra furto, roubo ou dano, crime de extorsão por conta de subtração de aparelho celular, bem como qualquer outro tipo em que o bem jurídico protegido não seja diretamente relacionado com a tecnologia aqui serão desprezados para melhor se atingirem os objetivos visados.

O leitor verá, entretanto, que há crimes que são cometidos com o uso da tecnologia mas que se assemelham a crimes comuns. Esses terão alguma atenção, apesar de serem de fácil identificação. 


\section{Crimes específicos da tecnologia móvel}

Certamente que a adoção de certas tecnologias pela telefonia móvel fez com que se alastrasse o uso desses avanços sendo, inclusive, alguns deles incorporados pelos próprios computadores.

A idéia da mobilidade trazida com a chegada dos aparelhos sem fio e em seguida os celulares normais e celulares por VoIP minimizava a idéia do uso de fios para a comunicação seja com outros aparelhos, seja mesmo com fones de ouvido ao fundir-se tocadores de música com aparelhos de telefonia móvel.

Destarte, a transmissão de dados por mecanismos de emissão e recepção de raios infravermelhos, a criação da tecnologia bluetooth de transmissão de dados a certa distância e a conectividade sem fio à Internet pela tecnologia WAP, wi-fi e mais recentemente a tecnologia wi-max foram e vão se incorporando à telefonia. E é o caráter de personificação do aparelho móvel, bem como a imprescindibilidade deste, que gerou a necessária interatividade dos aparelhos com os computadores, notebooks, palmtops rádios etc. Hoje é possível, inclusive, utilizar-se de uma frequêencia vazia (FM) de um rádio para que o celular toque as músicas em si contidas diretamente no aparelho do carro ou da sala.

Também o fato de se agregar aos celulares câmeras que filmam e fotografam trouxe a necessidade de se compatibilizar a transmissão de dados.

Desta forma, os critérios para que assumamos um crime como sendo da modalidade em referência, ou seja, crimes de telefonia móvel, são os seguintes: (a) a tecnologia deve estar incorporada em um aparelho de telefonia móvel; (b) a tecnologia deve ser suficiente para o cometimento do crime somente com uso de aparelho de telefonia móvel, sem precisar de outros aparatos; e (c) a tecnologia, se externa ao aparelho de telefonia móvel, deve existir especialmente para atingir o bem jurídico da telefonia móvel, ou seja, o aparelho, sinal, bateria, chip, câmera ou linha telefônica.

Alguns recursos de telefonia móvel são simplesmente análogos a outras tecnologias de uso diário. Assim, enquanto que por meio de uma conexão telefônica, ADSL, cabo ou mesmo rádio uma pessoa consegue enviar e-mails com conteúdo criminoso, certamente em nada diferirá o cometimento de condutas típicas por meio de e-mails enviados por tecnologia WAP, GPRS ou CDMA2000 (ou as exclusivas existentes em diversos países).

Enquanto que podemos imaginar uma situação típica de ameaça, injúria ou calúnia praticada por meio de e-mail, exemplificativamente a remessa de uma mensagem eletrônica contendo dizeres com animus específicos para cometimento de crimes, o mesmo se pode pensar no que se refere a celulares. Entretanto, imprescindível que se verifique se as companhias ou provedores registram os conteúdos dos e-mails enviados por telefonia móvel. E, mais do que isso, se há forma de se tracejar o caminho do agente ativo do crime e identificá-lo. É relativamente simples localizar a máquina que remeteu um e-mail pela Internet, uma vez que o pro- 
tocolo IP da máquina fica registrado no provedor. Entretanto, terão as operadoras de telefonia móvel o mesmo controle? Certamente que através da tecnologia VoIP sim, vez que é idêntica à situação do acesso feito através de computadores. Mas grandes dúvidas remanescem quanto ao envio feito hoje pelo celular que usa da tecnologia acima referida. Entretanto o crime em si é facilmente identificado, vez que somente a ferramenta utilizada para perpetrá-lo é especial. E idêntico seria se uma injúria fosse proferida por telégrafo ou sinais de fumaça.

Assunto curioso de tratar, entretanto, é o envio de mensagens por SMS (Short Messaging Service) e MMS (Multimedia Messaging Service). Certamente que crimes cometidos por meios destas tecnologias caem no mesmo lugar-comum acima tratado, ou seja, é penalmente irrelevante o meio utilizado quando o crime possui em sua essência a forma livre. Ocorre, entretanto, que não se consegue saber pelos sites oficiais de operadoras de telefonia móvel se há registro das mensagens que se envia através dessa tecnologia. Parece que, se analisarmos uma conta telefônica hoje, a operadora tem alguma espécie de registro, uma vez que há discriminação de envio das mensagens para aparelhos que trabalham com a mesma operadora e mensagens para aparelhos de outras operadoras.

Sabe-se que as conversas telefônicas são protegidas pelo sigilo. Entretanto, serão tais mensagens protegidas pelo mesmo sigilo ou será este sigilo o de dados? Cremos que seria considerado sigilo pelo mesmo fundamento jurídico constitucional, qual seja o artigo $5^{\circ}$, XII, da Carta Magna. Todavia, sabe-se que a quebra de sigilo telefônico difere da quebra de sigilo de mensagens de texto. A base disso é uma rápida pesquisa feita pela Internet. Não se encontra nenhuma notícia acerca de qualquer relação entre uma solicitada quebra de sigilo telefônico e o envio de mensagens.

Emblemático é o caso do assassinato do Coronel Ubiratan na cidade de São Paulo em setembro de 2006. Não se pediu especificamente quebra de sigilo quanto às mensagens enviadas. Mas, sim, se requereu que a Srta. Carla Cepollina cedesse seu aparelho de telefonia móvel para a polícia ${ }^{18}$ que, por sua vez, encaminhou-o à perícia técnica para avaliação. E foi esta perícia que trouxe a informação de que a moça havia remetido mensagens de texto para a vítima. Esse fato levanta dúvidas e reafirma a tese de que o armazenamento específico das mensagens enviadas através da tecnologia da telefonia aqui tratada (i) ou não está devidamente protegido pelas regras do sigilo telefônico ou (ii) está protegido mas as operadoras não armazenam tais dados.

A questão que se discute, pois, não é a ocorrência do crime que poderia se dar por qualquer meio, mas sim a dúvida no que se refere à materialidade do delito. Certamente que pelo princípio de presunção de inocência do réu não se poderá presumir que o conteúdo da mensagem enviada foi criminoso. Assim, no que se refere a certos crimes e o meio escolhido, não se conseguindo investigar a men-

18 Conforme notícia em <http://oglobo.globo.com/sp/mat/2006/09/13/285638252.asp>. 
sagem de texto em si, nunca se poderá concluir satisfatoriamente pela autoria. $\mathrm{E}$ é esta a dificuldade que levantamos neste trecho do trabalho. Torna-se imprescindível que o Direito Penal e a Polícia investigativa busquem meios para colher indícios de crimes eletrônicos, exemplificativamente desta natureza, outrossim criar-se-á mais cultura da impunidade.

Ainda no que se refere às tecnologias ainda principalmente utilizadas em telefonia móvel, ${ }^{19}$ há que se falar na tecnologia bluetooth. Este recurso serve para interconectar dispositivos de uso pessoal a curta distancia (até 10 metros), coordenando-as (pairing, como se denominou em inglês). É tecnologia de rádio com baixo custo e que tem se alastrando rapidamente. Entretanto, diversos fabricantes $^{20}$ já apontaram falhas de segurança em suas tecnologias, resultando em certa fragilidade no que toca à conectividade dessa tecnologia.

Com o surgimento da tecnologia bluetooth, junto vieram as vulnerabilidades e falhas de segurança. E, com elas, a criminalidade embarcou e passou a utilizar-se da tecnologia para a criação de crimes específicos.

As principais condutas delituosas surgidas com essa tecnologia foram o bluesnarfing, o bluejacking e o bluecasting. A nomenclatura adotada tem se mantido na língua inglesa por conta de os primeiros casos serem relatados nos Estados Unidos da América do Norte e todos os casos trazem como prefixo a palavra "blue", referindo-se à tecnologia bluetooth.

O bluejacking é a prática de envio de mensagens anônimas para outros usuários que estão no perímetro de funcionalidade da tecnologia bluetooth. Por conta de uma falha de segurança de alguns aparelhos, é possível remeter mensagens na forma de cartão de visita com qualquer espécie de conteúdo, desde que curta. Quando inofensiva, a prática é apelidada de bluedating - paquera por mensagens via tecnologia bluetooth - ou bluechating - bate-papo por mensagens via tecnologia bluetooth. Entretanto, nada impede que na prática utilize-se esse meio para mandar mensagens com conteúdos criminosos, seja ofendendo honra, ameaçando, perturbando, assediando ou importunando o pudor de outrem. Novamente $o$ crime é simples de identificar a priori, mas também traz em si um problema investigativo. Por conta de a remessa na modalidade bluejacking ser anônima e apócrifa em sua maioria, a investigação de autoria fica bastante restrita. Flagrantes seriam bastante possíveis, vez que o raio de atuação é de até 10 metros; todavia, uma vez fora do local dos fatos, ficaria praticamente impossível a descoberta do autor do delito que interessantemente não deixa rastros.

Já o bluesnarfing é uma prática mais perigosa. Enquanto que o bluejacking pode ter um sentido até inocente, o bluesnarfing requer grande alerta. Consiste na prática de se apropriar dos dados contidos em um aparelho de telefonia móvel sem

19 Não se pode esquecer que o desenvolvimento da tecnologia visa computadores, periféricos e PDA, bem como outros dispositivos.

20 Nokia, Sony Ericsson, Motorola e Palm, pelo menos, conforme percebe-se em: <http://www. bluejackq.com/how-to-bluejack.shtml>. 
deixar vestígios e utilizando-se da tecnologia bluetooth de transmissão. Fotos, filmes, agenda de compromissos, telefones, planos de negócio, arquivos de texto, apresentações de negócios, tudo o que for armazenado em um aparelho com brecha de segurança por conta da tecnologia citada está sujeito a, após uma invasão, ser copiado ou até apagado, sem contar a possibilidade de que o invasor utilize remotamente o celular para ligaçōes ou simplesmente o torne inoperante. Curiosamente, a simples cópia pode não configurar nenhum tipo de delito tipificado no Código Penal e leis esparsas. Quiçá um crime contra o privilégio de invenção, violação de segredo industrial, ou, em caso de corrupção de arquivos, um crime de dano ou uma violaçāo de sigilo, mas o destaque está na dificuldade de tipificação explícita, requerendo atitude imediata do legislador e talvez até criando uma agravante para o uso de tecnologias que dão privilégios de anonimato. $\mathrm{O}$ mesmo poderia se argumentar ao se considerar os telefonemas que trazem "número privativo" como identificação.

Vale citar que, assim como tem ocorrido na computação tradicional em que um agente utiliza-se de um keylogger e descobre nome e senha de conta de e-mail de um usuário, apagando toda a caixa de entrada ou modificando a senha e, em seguida, exigindo resgate para devolver o conteúdo, tal fato também pode ocorrer quanto à telefonia celular se o bluesnarfing desenvolver-se neste sentido. Destaque aos danos morais e econômicos advindos, o que exigirá do usuário, caso consiga uma condenação do agente, uma ação civil ex delicto como seria em qualquer crime com conseqüências cíveis.

Analogamente à idéia de spamming existente na computação, existe, também, na telefonia móvel uma modalidade de envio de mensagens de propaganda não desejadas. Isto ocorre pela própria operadora que remete propagandas próprias a qualquer hora do dia e por pessoas jurídicas que aproveitam falhas de segurança da tecnologia bluetooth e praticam o bluecasting. ${ }^{21}$ Esta prática consiste em, com ou sem o uso de um canhão de aumento de sinal bluetooth (bluesniper), varrer os arredores para encontrar celulares disponíveis para receberem spams. Encontrados os aparelhos móveis, enviam-se as mensagens indesejadas. Essa prática também ainda é pouco utilizada no Brasil mas tem crescido ao redor do mundo. Nossa legislação não prevê nenhum tipo de penalização para os praticantes de envio de mensagens não solicitadas e hoje, vivamente, se discute tal necessidade.

Também não muito difundida no Brasil está a prática de remessa de vírus elaborados especificamente para contaminarem aparelhos móveis. Detectou-se na Finlândia, por meio da empresa de antivírus F-Secure, a inoculação de um vírus denominado "Commwarrior.A" de origem russa. É um vírus que se transmite por mensagens MMS ou pela tecnologia bluetooth e tem pouco poder destrutivo. Entretanto; a existência de vírus para aparelhos móveis levará ao comércio de antivírus para celular bem como à propagação da criminalidade por este meio, uma

21 Inicialmente praticado na Inglaterra, conforme o site <http://publicidade.terra.com.br/noticias/2608_poster.html>. Publicado em 26 de agosto de 2005. Acesso em: 6 jan. 2007. 
vez que o contágio por vírus poderá destruir o sistema ou apagar dados (e então estar-se-ia diante de um tipo de crime de dano - art. 163 do CP), torná-lo lento excessivamente (furto de tempo) ou até mesmo difundir idéias criminosas ou apologias a crimes, dentre outras práticas.

Certamente que os formatos de vídeos e, em alguns aparelhos, fotografias, fundos de tela, toques, descansos de tela e gravações de voz podem ser de padrões diferentes dos utilizados na computação tradicional. Assim, gira um comércio de arquivos em formatos e tecnologias específicas para celulares. Certamente, por detrás desse comércio estão direitos autorais e intelectuais dos autores das mídias ou dados a serem utilizados pelo usuário da tecnologia de telefonia móvel. Ocorre que estamos diante do mesmo problema que assola o mercado fonográfico, mas com características de tecnologia especial.

O uso sem licença de músicas, vídeos ou quaisquer mídias configura violação de direitos autorais e, portanto, configura crime, de acordo com a Lei $\mathrm{n}^{\circ}$ 9.610/98, que regulamenta as sançōes civis contra o uso abusivo dos direitos autorais. Seria o caso de engrandecer a discussão acerca da tipificação penal mais rigorosa para este setor, apesar da Lei $n^{\circ} 9.279 / 96$ ? De qualquer maneira a tecnologia é específica mas o problema com o uso ilegal e indevido de mídias registradas e patenteadas é o mesmo que assola a computação costumeira.

Ainda não muito comum no Brasil, mas em países de desenvolvimento avançado como o Japão, novos celulares têm sido produzidos com capacidade de comunicação com operadoras de cartão de crédito e até mesmo com vending machines (máquinas de rua que fazem vendas de refrigerante, livros etc.). Assim, dispensando o dinheiro, um usuário pode carregar seu celular com créditos para serem utilizados da forma como bem entender. E aqui a evolução é muito útil e interessante e traz, como em todos os avanços da tecnologia, problemas jurídico-penais, uma vez que falsificações de chips com crédito, burlas a sistemas para se conseguir créditos e invasão de sistemas para se conseguir efetuar compras ardilosas pelo celular surgirão, bem como aparatos capazes de apropriarem-se de créditos alheios ou controlar remotamente celulares alheios clonando-os ou simplesmente emprestando créditos, serão formas de se contravir.

Também bastante recente é a tecnologia que permite que um usuário, através de seu celular, verifique as câmeras de segurança de sua casa, encontre alguém por tecnologia GPS, ligue e desligue seu alarme de casa, prepare seu banho, ligue as luzes, abra a porta da garagem entre tantas outras funcionalidades. Observe-se que, quanto mais dependente o indivíduo se torna de seu aparelho celular (ou de qualquer aparelho), maior alvo de delitos esta tecnologia tornar-se-á. Possível é imaginar que os futuros aparatos para invadir sistemas sejam dispositivos capazes de infiltrar-se nos controles equivalentes ao de celulares e, portanto, infiltrar-se em sistemas virtuais através de ondas. Uma vez tomado o controle, poderá o infrator olhar através das câmeras da casa, desligar os alarmes (usando o celular como uma forma de chave falsa), seguir uma pessoa etc. Aliás, conjugadamente 
com a tecnologia bluetooth, o bluesnarfing hoje já permite que se conheça a agenda de compromisso, os amigos e até mesmo os gastos de um usuário. O futuro tente a trazer mais formas de criminalidade através de invasão e controle de celulares, vez que os aparelhos estão mais integrados. Por certo, empresas iniciarão contraataques, com firewalls para celulares, antivírus e correções de falhas de segurança, mas a criminalidade costuma estar um passo à frente sempre.

A clonagem de linhas de telefonia móvel também tem se alastrado. Assim, utilizando-se de aparelhos especiais, um agente ativo é capaz de copiar a linha telefônica de outrem e utilizá-la como se proprietário fosse. Certamente é uma forma de estelionato, qualificada pelo uso de tecnologia e existente por falhas de segurança dos próprios aparelhos.

Ainda sobre o tema, interessante avaliarmos se a conduta de desbloquear aparelhos de telefonia móvel de outras operadoras funciona com qualquer operadora. Poderia a atitude ser considerada uma forma de estelionato? Parece-nos que não, uma vez que não há ardil ou fraude, nem induzimento ou manutenção de erro, pois o travamento do aparelho para funcionamento é uma estratégia de marketing das operadoras especificamente, sendo lícito buscar-se serviço especializado para reverter o travamento. Entretanto, importante avaliar se o destravamento é feito por pessoa com conhecimento especializado ou por alguém que incide no tipo penal da violação do segredo de fábrica ou negócio (art. 196, XII, Código Penal). Se estiver o agente diante de tal tipo, responderá pelas condutas. Não se tipificando como crime a conduta de destravamento de aparelho, não há que se falar em receptação por parte daquele que fica com o aparelho.

Há que se dedicar algumas linhas quanto ao usuário da telefonia celular e seu impacto diante da criminalidade específica. Os principais usuários das novas tecnologias, em regra, são os jovens. Estatísticas mostram que $67 \%$ dos usuários de telefonia móvel são jovens entre 16 e 25 anos. ${ }^{22}$ Destarte, boa parte das atitudes criminosas é cometida por indivíduos abaixo da maioridade penal. Desnecessário comentar acerca da imputabilidade dos agentes ativos dos delitos, bem como da praticamente impossível possibilidade de internação de criança ou adolescente por execução de crimes desta natureza, uma vez que raramente trazem violências em sua essência.

Ainda quanto aos usuários da telefonia móvel devemos considerar que a telefonia celular, em especial a pré-paga, pode ser considerada praticamente anônima. Ainda que se exija um cadastro do telefone, este pode facilmente ser doado, emprestado, vendido, furtado, roubado ou até mesmo perdido, perdendo-se a presunção de posse e, com ela, a presunção da autoria da atitude típica. Assim, é de se ressaltar que há uma grande dificuldade no que se refere à investigação de autoria, ainda mais porque a mobilidade dos aparelhos (que é obviamente de sua essência) o torna facilmente alienável e destrutível. Também, não se pode esquecer do uso de falsa identidade por parte dos usuários de telefonia móvel.

22 <http://cidadebiz.oi.com.br/paginas/34001_35000/34946-1.html>, em referência ao Instituto Datafolha. 


\section{Conclusões}

1. Definitivamente o futuro chegou. Chegou e já se tornou obsoleto. Não há como negar que a tecnologia atual está em franco desenvolvimento, de modo que a denominação "última geração" tem conotação sazonal. A última novidade será superada e esquecida no ano seguinte. Ou talvez apenas meses depois.

2. Não há como aferir o futuro grau de desenvolvimento tecnológico precisamente. Uma "simples" descoberta pode significar uma infinidade de novas tecnologias em curtíssimo espaço de tempo.

3. Justamente em razão de não se poder precisar como o desenvolvimento tecnológico ocorrerá em curto tempo, não se pode ser hipócrita e querer dominar todas as espécies de tecnologia. O leque se abriu de tal forma, que é impossível "dominar a tecnologia".

4. Em razão disso, quando falamos em criminalidade informática, não podemos pensar simplesmente em criminalizar toda e qualquer conduta. Já estamos a algum tempo em fase de "inflação penal", de modo que novas tipificaçōes somente devem ser efetivadas depois de muito estudo e ponderação.

5. Em se desejando tipificar condutas específicas destinadas contra um sistema informático, não se podem olvidar corolários básicos do direito penal como o princípio da legalidade, o da reserva legal, o da lex certa. Isso porque os tipos penais, em razão da grande e rápida atualização das modalidades criminosas modernas, não podem vir a ser redigidos de forma aberta. Será preciso criminalizar, mas sem que se preveja punição a risco hipotético (mais correto seria chegar apenas ao perigo concreto).

6. Conseqüência óbvia do crescente desenvolvimento da telemática é a impossibilidade de se fazer tipificação penal considerando-se o meio (instrumento) de execução. Isso em razão da rápida modificação da tecnologia. Vislumbramos, então, eventual dificuldade na tipificação, que, segundo nossos princípios constitucionais, deve ser fechada. A rápida mutabilidade da tecnologia pode, de alguma forma, impedir que certas condutas sejam tipificadas.

7. Nem todas as condutas que julgamos criminosas são novidades trazidas pela telemática, pelo que podem eventualmente ser punidas segundo a legislação penal existente. É o caso de se utilizar a telemática para a perpetraçāo de crimes comuns (ex. estelionato aplicado por mensagens de e-mail).

8. A despeito de haver condutas criminosas já tipificadas em nosso ordenamento, imprescindível voltar nossos olhos às novas tecnologias de modo a tipificar determinadas condutas que são violadoras de sis- 
temas informáticos. É o caso dos delitos informáticos puros (ex. dano a arquivo digital). Todavia, ressaltamos as idéias acima expostas sobre tipicidade fechada e o rápido avanço tecnológico.

9. Quanto às fraudes em relação a documentos digitais, não propomos um novo conceito para documentos em geral, mas não se pode negar que arquivos digitais têm importância econômica, jurídica e, por que não dizer, até mesmo sentimental, de modo que devem receber proteção legal contra eventuais violações que venham a sofrer. Destarte, devemos ter em mente duas modalidades distintas de documentos, o convencional (corpóreo) e o moderno (digital), cada qual com suas peculiaridades.

10. Em relação aos meios de prova, com a telemática será preciso que nossos órgãos policiais se aprimorem cada vez mais. Será de suma importância haver peritos informáticos realmente com ótimo conhecimento e capacidade de atualização, mas também que haja condições materiais de trabalho (equipamentos modernos). Não podemos pensar em investigação séria se ainda encontramos máquinas de escrever nas delegacias. Toda a polícia deve ser reestruturada com vistas a melhor investigação. Note que isso não servirá apenas aos delitos informáticos. Há que se investir em inteligência, tecnologia.

11. Ainda quanto aos meios de prova, será preciso fazer uma releitura do que é permitido provar e como isso será demonstrado no processo, vez que os eventuais vestígios deixados por crimes informáticos têm sua captação de forma peculiar.

12. É preciso repensar os conceitos de territorialidade e extraterritorialidade penal vez que crimes informáticos muitas vezes ganham caráter transnacional. E, pela possibilidade de haver vários intermediários (agressor num país, provedor de acesso em outro e vítima em outro ainda), faz-se necessário adequar as regras de aplicação do direito penal a tais infrações, inclusive com a celebração de tratados internacionais.

13. Parece-nos claro que, apesar de todos os avanços tecnológicos a que nos referimos, ainda levaremos certo tempo até que nossa legislação se torne mais adequada às necessidades da vida moderna. E não estamos considerando que será necessária reforma total imediata.

14. É preciso, além de pensar em novas formas de combater a criminalidade informática, que sejamos mais dedicados e criativos quanto a nossa dogmática penal. Não se pode conceber tratarmos de crimes onde a telemática está diretamente envolvida e, ao mesmo tempo, nos apegarmos fervorosamente ao Finalismo. Mister se faz pensarmos em teorias mais modernas, ingressando no Funcionalismo Penal, especialmente por meio da Teoria da Imputação Objetiva. 


\section{Glossário específico (fonte: <http://cartilha.cert.br/glossario/>)}

Antivírus: Programa ou software especificamente desenvolvido para detectar, anular e eliminar de um computador vírus e outros tipos de código malicioso.

Atacante: Pessoa responsável pela realização de um ataque.

Ataque: Tentativa, bem ou mal-sucedida, de acesso ou uso não autorizado a um programa ou computador. Também são considerados ataques as tentativas de negação de serviço.

Backdoor: Programa que permite a um invasor retornar a um computador comprometido. Normalmente este programa é colocado de forma a não ser notado.

Bit: Sinônimo de dígito binário. É a menor parcela de informação processada por um computador.

Bluetooth: Termo que se refere a uma tecnologia de rádio-freqüência (RF) de baixo alcance, utilizada para a transmissão de voz e dados.

Cavalo de Tróia: Programa, normalmente recebido como um "presente" (por exemplo, cartão virtual, álbum de fotos, protetor de tela, jogo etc.), que além de executar funções para as quais foi aparentemente projetado, também executa outras funções normalmente maliciosas e sem o conhecimento do usuário.

Código malicioso: Termo genérico que se refere a todos os tipos de programa que executam ações maliciosas em um computador. Exemplos de códigos maliciosos são os vírus, worms, bots, cavalos de tróia, rootkits etc.

Criptografia: Ciência e arte de escrever mensagens em forma cifrada ou em código. É parte de um campo de estudos que trata das comunicações secretas. É usada, dentre outras finalidades, para: autenticar a identidade de usuários; autenticar transaçōes bancárias; proteger a integridade de transferências eletrônicas de fundos; e proteger o sigilo de comunicações pessoais e comerciais.

Endereço IP: Este endereço é um número único para cada computador conectado à Internet, composto por uma seqüência de quatro números que variam de 0 até 255, separados por “.". Por exemplo: 192.168.34.25.

Engenharia social: Método de ataque onde uma pessoa faz uso da persuasão, muitas vezes abusando da ingenuidade ou confiança do usuário, para obter informaçōes que podem ser utilizadas para ter acesso não autorizado a computadores ou informaçōes.

Firewall: Dispositivo constituído pela combinação de software e hardware, utilizado para dividir e controlar o acesso entre redes de computadores.

Firewall pessoal: Software ou programa utilizado para proteger um computador contra acessos não autorizados vindos da Internet. É um tipo específico de firewall. 
Falsa identidade: Ato onde o falsificador atribui-se identidade ilegítima, podendo se fazer passar por outra pessoa, com objetivo de obter vantagens indevidas, como por exemplo, obter crédito, furtar dinheiro de contas bancárias das vítimas, utilizar cartões de crédito de terceiros, entre outras.

Hardware: Conjunto dos componentes físicos (material eletrônico, placas, monitor, equipamentos periféricos etc.) de um computador.

Keylogger: Programa capaz de capturar e armazenar as teclas digitadas pelo usuário no teclado de um computador. Normalmente, a ativação do keylogger é condicionada a uma ação prévia do usuário, como, por exemplo, após o acesso a um site de comércio eletrônico ou Internet banking, para a captura de senhas bancárias ou números de cartões de crédito.

Malware: Do Inglês Malicious software (software malicioso). Veja Código malicioso.

MMS: Do Inglês Multimedia Message Service. Tecnologia amplamente utilizada em telefonia celular para a transmissão de dados, como texto, imagem, áudio e vídeo.

Phishing: Também conhecido como phishing scam ou phishing/scam. Mensagem não solicitada que se passa por comunicação de uma instituição conhecida, como um banco, empresa ou site popular, e que procura induzir usuários ao fornecimento de dados pessoais e financeiros. Inicialmente, este tipo de mensagem induzia o usuário ao acesso a páginas fraudulentas na Internet. Atualmente, o termo também se refere à mensagem que induz o usuário à instalação de códigos maliciosos, além da mensagem que, no próprio conteúdo, apresenta formulários para o preenchimento e envio de dados pessoais e financeiros.

Rootkit: Conjunto de programas que tem como finalidade esconder e assegurar a presença de um invasor em um computador comprometido. É importante ressaltar que o nome rootkit não indica que as ferramentas que o compōem são usadas para obter acesso privilegiado (root ou administrator) em um computador, mas sim para manter o acesso privilegiado em um computador previamente comprometido.

Scam: Esquemas ou ações enganosas e/ou fraudulentas. Normalmente, têm como finalidade obter vantagens financeiras.

Screenlogger: Forma avançada de keylogger, capaz de armazenar a posiçāo do cursor e a tela apresentada no monitor, nos momentos em que o mouse é clicado, ou armazenar a região que circunda a posição onde o mouse é clicado. Veja também Keylogger.

Senha: Conjunto de caracteres, de conhecimento único do usuário, utilizado no processo de verificação de sua identidade, assegurando que ele é realmente quem diz ser. 
Site: Local na Internet identificado por um nome de domínio, constituído por uma ou mais páginas de hipertexto, que podem conter textos, gráficos e informações multimídia.

SMS: Do inglês Short Message Service. Tecnologia amplamente utilizada em telefonia celular para a transmissão de mensagens de texto curtas. Diferente do MMS, permite apenas dados do tipo texto e cada mensagem é limitada em 160 caracteres alfanuméricos.

Sniffer: Dispositivo ou programa de computador utilizado para capturar e armazenar dados trafegando em uma rede de computadores. Pode ser usado por um invasor para capturar informações sensíveis (como senhas de usuários), em casos onde estejam sendo utilizadas conexões inseguras, ou seja, sem criptografia.

Spam: Termo usado para se referir aos e-mails não solicitados, que geralmente são enviados para um grande número de pessoas. Quando o conteúdo é exclusivamente comercial, este tipo de mensagem também é referenciada como UCE (do Inglês Unsolicited Commercial E-mail).

Spammer: Pessoa que envia spam.

Spyware: Termo utilizado para se referir a uma grande categoria de software que tem o objetivo de monitorar atividades de um sistema e enviar as informaçōes coletadas para terceiros. Pode ser utilizado de forma legítima, mas, na maioria das vezes, é utilizado de forma dissimulada, não autorizada e maliciosa.

Trojan horse: Veja Cavalo de Tróia.

UCE: Do inglês Unsolicited Commercial E-mail. Termo usado para se referir aos emails comerciais não solicitados.

Vírus: Programa ou parte de um programa de computador, normalmente malicioso, que se propaga infectando, isto é, inserindo cópias de si mesmo e se tornando parte de outros programas e arquivos de um computador. $O$ vírus depende da execução do programa ou arquivo hospedeiro para que possa se tornar ativo e dar continuidade ao processo de infecção.

Vulnerabilidade: Falha no projeto, implementação ou configuração de um software ou sistema operacional que, quando explorada por um atacante, resulta na violação da segurança de um computador.

Wi-Fi: Do inglês Wireless Fidelity. Termo usado para se referir genericamente a redes sem fro que utilizam qualquer um dos padrões 802.11.

Worm: Programa capaz de se propagar automaticamente através de redes, enviando cópias de si mesmo de computador para computador. Diferentemente do vírus, o worm não embute cópias de si mesmo em outros programas ou arquivos e não necessita ser explicitamente executado para se propagar. Sua propagação se dá através da exploração de vulnerabilidades existentes ou falhas na configuração de softwares instalados em computadores. 


\section{Referências}

\section{Bibliográficas}

AMARAL, Sylvio do. Falsidade documental. Campinas: Millenium, 2000.

CORRÊA, Gustavo Testa. Aspectos jurídicos da Internet. São Paulo: Saraiva, 2000.

DE LUCCA, Newton; SIMÃO FILHO, Adalberto (Coord.). Direito e Internet: aspectos jurídicos relevantes. São Paulo: Edipro, 2001.

GOUVÊA, Sandra. O direito na era digital. Rio de Janeiro: Mauad, 1997.

LIMA, Paulo Marco Ferreira. Crimes de computador e segurança computacional. Campinas: Millennium, 2006.

MARCACINI, Augusto Tavares Rosa. O documento eletrônico como meio de prova. Revista eletrônica Avocati Locus, seção Artigos \& Doutrina. Disponível em: <www.advogado.com.br>. Acesso em: 9 jan. 2007.

MIRABETE, Julio Fabbrini. Manual de direito penal. 22. ed. São Paulo: Saraiva, 2004. v. 2.

REIS, Maria Helena Junqueira. Computer crimes. Belo Horizonte: Del Rey, 1997.

SILVA, Rita de Cássia Lopes da. Direito penal e sistema informático. São Paulo: Revista dos Tribunais, 2003.

\section{Eletrônicas}

<http://cartilha.cert.br>.

<http://news.zdnet.co.uk/internet/security/0,39020375,39146427,00.htm>.

<http://www.timesonline.co.uk/printFriendly/0,,1-7-1072761,00.html >.

<http://news.bbc.co.uk/1/hi/technology/3237755.stm>.

<http://news.zdnet.co.uk/communications/wireless/0,39020348,39145881,00.

htm>.

$<$ http://publicidade.terra.com.br/noticias/2608_poster.html $>$.

$<$ http://informatica.terra.com.br/interna/0,,OI484399-EI559,00.html >.

<http://e-opportunities.blogspot.com/search/label/SPLOG>. 